\title{
DETERMINAÇÃO DA VIABILIDADE CELULAR DE BACTÉRIAS LÁTICAS SUBMETIDAS A DIFERENTES MÉTODOS DE PRESERVAÇÃO
}

\author{
$\underline{\text { July Ane Barreto Martins }}{ }^{1}$; Elinalva Maciel Paulo² ; Fabrícia Santiago Carneiro $^{3}$ \\ 1. Bolsista PIBIC/FAPESB, Graduanda em Engenharia de Alimentos, Universidade Estadual de Feira de Santana, \\ e-mail: julyanemartins@ hotmail.com \\ 2. Orientadora, Departamento de Ciências Biológicas, Universidade Estadual de Feira de Santana, e-mail: \\ elinalvamaciel@yahoo.com.br \\ 3. Graduanda em Farmácia, Universidade Estadual de Feira de Santana, e-mail: fabryciacarneiro@ gmail.com
}

PALAVRAS-CHAVE: Bactéria láctica, preservação bacteriana, semiárido baiano.

\section{INTRODUÇÃO}

O isolamento, identificação, conservação e uso de micro-organismos se caracterizam como prática imprescindível para o desenvolvimento de pesquisas, processos e obtenção de produtos de interesse econômico. Para que se utilizem tais recursos, é necessário manter os micro-organismos viáveis (GIRÃO et al., 2004). Segundo Paoli (2005), a implantação e manutenção de coleções de culturas permitem a formação de estoques de cepas, que podem ser utilizadas experimentalmente em diferentes momentos.

Por isso a importância da manutenção e principalmente preservação de culturas bacterianas advém da necessidade de se dispor do organismo ou espécime a qualquer momento, quer para fins experimentais, didáticos, industriais ou estudos comparativos. Desta forma, conhecer a melhor maneira de preservar culturas bacterianas e dispor de técnicas simples e eficientes para tanto, reveste-se de grande valia aos laboratórios de microbiologia.

\section{MATERIAIS E MÉTODOS}

Foram utilizadas duas espécies de bactérias láticas; uma isolada do leite (Lactobacillus plantarun U205) e a outra do leite de cabra (Streptococcus thermophylus LCMH01). Ambas as espécies de bactérias láticas foram submetidas a três processos de preservação:

\section{Refrigeração}

As culturas bacterianas ativas de cada espécie foram repicadas em tubos de cultura rosqueáveis contendo $5 \mathrm{~mL}$ de ágar inclinado de MRS modificado ( $0,5 \%$ de glicose). Os tubos foram incubados a $30^{\circ} \mathrm{C}$ até o aparecimento do crescimento celular, sendo depois acondicionados em refrigerador a $6^{\circ} \mathrm{C} \pm 1$.

\section{Congelamento $\left(-18^{\circ} \mathrm{C}\right)$}

As culturas bacterianas ativas de cada espécie foram semeadas por estrias compostas em placas de Petri, contendo ágar MRS, e incubadas a $30^{\circ} \mathrm{C} / 72 \mathrm{~h}$. Após esse período foi adicionado em cada placa contendo uma expressiva massa bacteriana, $15 \mathrm{~mL}$ de solução salina tampão fosfato, e a seguir transferido $30 \mu \mathrm{L}$ desta suspensão para criotubos, contendo $1,5 \mathrm{~mL}$ de leite desnatado reconstituídos, acrescido de extrato de levedura e glicose (BADIS, et al., 2004). Todos os criotubos foram acondicionados em congelador comum $\left(-18^{\circ} \mathrm{C}\right)$.

\section{Liofilização}

As culturas bacterianas ativas de cada espécie foram ativadas em placas de Petri, contendo ágar MRS, incubados a $30^{\circ} \mathrm{C} / 72 \mathrm{~h}$. Após esse período foi adicionado em cada placa contendo expressiva massa bacteriana, $15 \mathrm{~mL}$ de solução salina tampão fosfato, e a seguir 
transferido $1 \mathrm{~mL}$ desta suspensão para frascos de vidro, contendo $2 \mathrm{~mL}$ de leite desnatado reconstituído, acrescido de extrato de levedura e glicose (BADIS, et al., 2004). Todos os tubos foram acondicionados em ultrafrezeer $\left(-80^{\circ} \mathrm{C}\right)$ para congelamento das amostras, sendo em seguida liofilizadas. Após o processo final da liofilização, os tubos contendo as células desidratadas, foram acondicionados em temperatura ambiente.

\section{Determinação da viabilidade celular.}

Mensalmente foi realizada contagem celular de cada isolado submetido aos três métodos de preservação. Para tal, utilizou-se o método de semeadura por profundidade no ágar MRS, sendo as placas incubadas a $30^{\circ} \mathrm{C} / 72 \mathrm{~h}$. Os resultados foram interpretados em unidade formadora de colônias (UFC) (PAULO, 2010).

Os dados da viabilidade celular de todos os métodos aplicados foram avaliados pela ANOVA (Microsoft Excel 2013) e realizado o teste de Tukey (ASSISTAT Versão 7.7 beta 2016) para a determinação do melhor método de preservação em termo de contagem de células viáveis durante o período estocado.

\section{RESULTADOS E DISCUSSÃO}

Na tabela 1 podem-se observar os resultados da contagem de células viáveis das espécies de bactérias láticas em estudo, submetidas aos três processos de preservação.

Tabela 1. Acompanhamento da viabilidade celular em unidade formadora de colônia (UFC) dos isolados de bactérias láticas Lactobacillus plantarun U205 e Streptococcus thermophylus LCMH01 nos diferentes métodos de preservação.

\begin{tabular}{|c|c|c|c|c|c|c|}
\hline Bactérias & \multicolumn{3}{|c|}{ Lactobacillus plantarum U205 } & \multicolumn{3}{|c|}{ Streptococcus thermophylus LCMH01 } \\
\hline Mês & 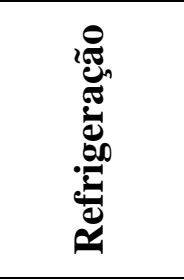 & 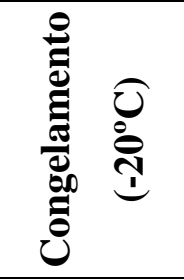 & 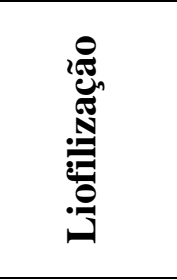 & 赵 & 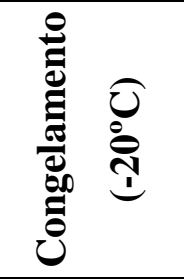 & 赵 \\
\hline Outubro & $9,63 \times 10^{8}$ & $2,12 \times 10^{8}$ & $2,77 \times 10^{7}$ & $1,62 \times 10^{8}$ & $7,60 \times 10^{7}$ & $3,53 \times 10^{7}$ \\
\hline Novembro & $1,05 \times 10^{9}$ & $1,98 \times 10^{8}$ & $1,46 \times 10^{7}$ & $2,57 \times 10^{8}$ & $5,17 \times 10^{7}$ & $1,83 \times 10^{7}$ \\
\hline Dezembro & $2,18 \times 10^{9}$ & $8,75 \times 10^{7}$ & $4,22 \times 10^{6}$ & $4,34 \times 10^{8}$ & $8,27 \times 10^{6}$ & $6,38 \times 10^{6}$ \\
\hline Janeiro & $3,25 \times 10^{9}$ & $5,11 \times 10^{7}$ & $2,47 \times 10^{6}$ & $1,10 \times 10^{9}$ & $6,31 \times 10^{6}$ & $4,69 \times 10^{6}$ \\
\hline Fevereiro & $4,63 \times 10^{9}$ & $3,91 \times 10^{6}$ & $1,19 \times 10^{6}$ & $2,39 \times 10^{9}$ & $3,02 \times 10^{6}$ & $1,32 \times 10^{6}$ \\
\hline Março & $7,82 \times 10^{8}$ & $1,42 \times 10^{6}$ & $-*$ & $1,32 \times 10^{9}$ & $1,59 \times 10^{6}$ & $-*$ \\
\hline Abril & $6,50 \times 10^{8}$ & $8,53 \times 10^{5}$ & $1,89 \times 10^{4}$ & $7,85 \times 10^{8}$ & $7,01 \times 10^{5}$ & $2,31 \times 10^{4}$ \\
\hline Maio & $4,71 \times 10^{8}$ & $5,22 \times 10^{5}$ & $1,20 \times 10^{3}$ & $4,53 \times 10^{8}$ & $4,14 \times 10^{5}$ & $4,53 \times 10^{3}$ \\
\hline Junho & $5,23 \times 10^{7}$ & $3,31 \times 10^{5}$ & $1,01 \times 10^{3}$ & $1,45 \times 10^{8}$ & $1,01 \times 10^{5}$ & $3,23 \times 10^{3}$ \\
\hline Julho & $1,05 \times 10^{7}$ & $1,25 \times 10^{5}$ & $9,72 \times 10^{2}$ & $1,06 \times 10^{8}$ & $8,97 \times 10^{4}$ & $1,15 \times 10^{3}$ \\
\hline
\end{tabular}

*Não realizado. 
Analisando os resultados obtidos percebe-se que no método de refrigeração tanto para o Lactobacillus plantarum U205 quanto para o Streptococcus thermophylus LCMH01 as bactérias mantiveram boa viabilidade celular, ocorrendo lentamente um decréscimo durante o período de armazenamento. Isso ocorreu devido o meio de crescimento/preservação ter sido constituído de baixa concentração de glicose, ocasionando a redução do metabolismo celular e consequentemente menor acidificação do meio, preservando por mais tempo as células microbianas.

Observando os resultados para as células que ficaram congeladas a $-18^{\circ} \mathrm{C}$, nota-se que para as duas bactérias ocorreu uma redução significativa comparado aos resultados das células refrigeradas. Uma possível explicação, segundo Romeiro (2006) é que a formação de cristais de gelo e a variação eletrolítica na faixa de temperatura utilizada podem causar danos às células.

Comparando os resultados obtidos para o método da liofilização, foi observado também um decréscimo significativo para as duas espécies das bactérias láticas. Uma possível justificativa é que conforme Morgan et al. (2006) os procedimentos de estocagem e acondicionamento influenciam significativamente na vida de prateleira dos materiais liofilizados. Como os isolados foram preservados a temperatura ambiente, acredita-se que este fator influenciou no decréscimo significativo dos micro-organismos.

Através da avaliação dos dados pela ANOVA foi observado para ambas as bactérias, que existe uma diferença significativa $(\mathrm{P}<0,05)$ entre os métodos de conservação, sendo possível observar pelo teste Tukey, que a média de UFC para os métodos de Congelado e Liofilizado foram estatisticamente iguais, já para o método de Refrigeração mostrou-se que a média de UFC é diferente dos demais, sendo superior aos outros dois métodos, demonstrando que a Refrigeração foi o melhor método de conservação dentre os testados nas condições aplicadas deste experimento.

\section{CONCLUSÃO}

Diante dos resultados obtidos neste experimento, nota-se que dentre os métodos estudados, o método de preservação por Refrigeração com baixa redução de glicose no meio, é um excelente método de preservação, pois além de ter garantido a manutenção da viabilidade celular durante os meses avaliados, não requer equipamento sofisticado.

No entanto sugere-se que sejam realizados com as mesmas espécies de bactérias utilizadas nesta pesquisa outros testes de preservação pela liofilização, sendo as amostras acondicionadas em baixas temperaturas, uma vez que, este método é considerado como o mais eficiente e de preservação a longo prazo.

\section{REFERÊNCIAS}

BADIS, A.; LUDWIG, W;SCHLEIFER, K. H. Identification and technological properties of lactic acid bacteria isolated from raw goat milk of four Algerian races. Food Microbiology. V. 21, n. 2. 579-588, 2004.

GIRÃO, M. D.; PRADO, M. R.; BRILHANTE, R. S. N.; CORDEIRO, R. A.; MONTEIRO, A. J.; SIDRIM, J. J. C.; ROCHA, M. F. G. Viabilidade de cepas de Malassezia pachydermatis mantidas em diferentes métodos de conservação. Revista da Sociedade Brasileira de Medicina Tropical, Rio de Janeiro, v.37, n.3,p. 229-233, mai/jun. 2004.

MORGAN, C. A.; HERMAN, N.; WHITE, P. A.; VESEY, G. Preservation of microorganisms by drying - a review. Journal of Microbiological Methods, Amsterdam, v.66, n.2, 
p.183-193, ago. 2006. Disponível em: 〈http://www.ncbi.nlm.nih.gov/pubmed/16632005> Acesso em 07 set. 2016.

PAOLI, P. Biobancos microbiologicos a partir de coleta de amostras para a epidemiologia, diagnóstico e pesquisa. FEMS Microbiol Rev. v. 29, pg. 897-910, 2005.

PAULO, E. M. 2010. Produção de exopolissacarídeos (EPS) por bactérias láticas visando microencapsulação de Lactobacillus acidophilus La-5 pelo processo de Spray drying. 2010. Tese 212f. (Doutorado em Biotecnologia), Departamento de Ciências Biológicas, Universidade Estadual de Feira de Santana, Feira de Santana, 2010.

ROMEIRO, R. S. Preservação de culturas de bactérias fitopatogênicas. Material didático, Laboratório de Bacteriologia de Plantas, Departamento de Fitopatologia, Universidade Federal de Viçosa, 2006. 